\title{
Конденсаторы переменной емкости
}

\section{Часть 2}

\author{
В. Кочемасов, к. т. н. ${ }^{1}$, С. Хорев ${ }^{2}$
}

УДК 621.319.4 | ВАК 05.27.01

\author{
В первой части статьи, опубликованной в шестом номере журнала \\ "ЭЛЕКТРОНИКА: Наука, Технология, Бизнес" за 2019 год, было рассказано \\ о нескольких типах конденсаторов переменной емкости. В данном номере \\ рассматриваются другие типы таких конденсаторов.
}

\section{Конденсаторы на основе стекла}

Этот тип устройств относится к конденсаторам с твердым неорганическим диэлектриком. К этому же классу относятся и пленочные конденсаторы с диэлектриком из твердых неорганических пленок. Но, тем не менее, многие компании-производители выделяют стеклянные конденсаторы в отдельный класс. Это связано с особенностями стекла как диэлектрика. Исторически стеклянные конденсаторы создавались на замену слюдяным, поскольку стекло обладает более высокой электрической прочностью при меньших толщинах и имеет более высокую диэлектрическую постоянную. Кроме того, стекло более теплостойкое и имеет хорошую свариваемость с металлами. С развитием новых технологий производства стекла появились новые соединения, такие как стеклокерамика (другие названия пирокерамика или фотокерамика) или стеклоэмаль. Это дало возможность изготавливать конденсаторы на основе стекла для самых разных областей применения. Отличительные особенности стекла как диэлектрика - высокая теплостойкость и линейная зависимость диэлектрической постоянной от температуры. Поэтому стеклянные конденсаторы имеют практически линейный ТКЕ, как это показано на рис. 12 [15].

Кроме того, стекло значительно более устойчиво к внешнему радиационному воздействию, чем другие материалы, применяемые при производстве конденсаторов, что позволяет использовать стеклянные конденсаторы в условиях, когда другие типы конденсаторов выходят из строя.

Конструктивно подстроечные и переменные конденсаторы на основе стекла выполняются так же, как и на основе других диэлектриков, с тем отличием, что чаще всего электроды в стеклянных конденсаторах изготавливаются напылением серебра. Для некоторых приложений это делает стеклянные триммеры более дорогими, чем, например, слюдяные или керамические. На рис. 13 [16]

ООО «Радиокомп», генеральный директор,

vkochemasov@radiocomp.ru.

о०० «Радиокомп», ведущий инженер, siw1937@yandex.ru. приведена фотография стеклянного триммера серии S компании Voltronics.

\section{Конденсаторы на основе кварца}

Кварц является одним из видов стекла и представляет собой чистый диоксид кремния $\mathrm{SiO}_{2}$, так называемое бесщелочное силикатное стекло. При производстве конденсаторов применяют искусственный кварц или так называемый плавленый кварц, поскольку в силу высокой твердости кварца обработка естественных кристаллов приводит к резкому удорожанию изделий. Кварц имеет наименьшее значение температурного коэффициента линейного расширения из всех известных материалов, поэтому его электрические и механические свойства мало зависят от температуры. Высокая механическая прочность кварца (его твердость по шкале Мооса равна 7) в сочетании с малым температурным коэффициентом линейного расширения делает кварцевые конденсаторы устойчивыми к тепловым импульсам и ударам. Диэлектрическая постоянная кварца на частоте 10 ГГц меняется от 3,8 при температуре $20^{\circ} \mathrm{C}$ до 4,0 при температуре $1000^{\circ} \mathrm{C}$. Как материал для конденсаторов кварц

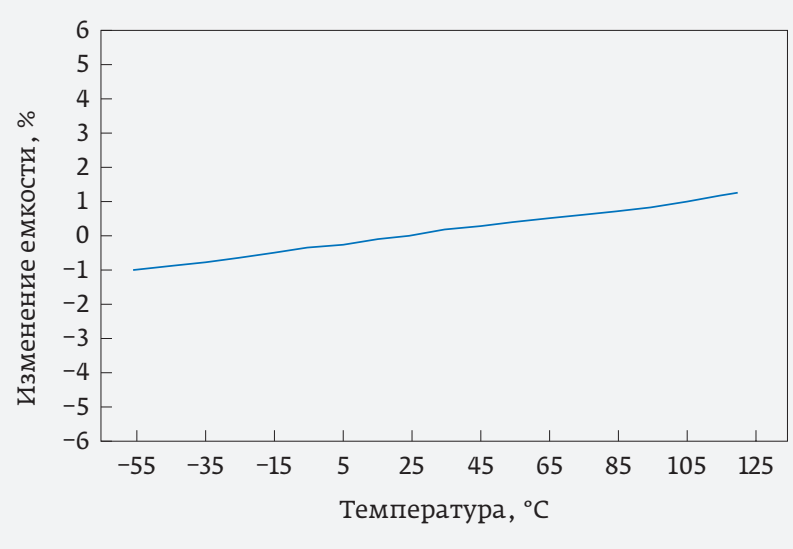

Рис. 12. Зависимость изменения емкости стеклянного конденсатора от температуры 


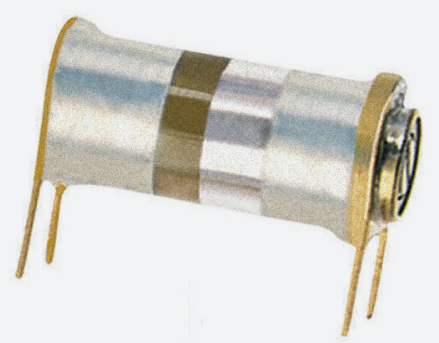

Рис. 13. Стеклянный триммер серии S компании Voltronics

обладает высокой электрической прочностью, что дает возможность применять кварцевые конденсаторы в высоковольтных устройствах. Вместе с тем кварц относится к классу пьезоэлектриков, что обязательно необходимо учитывать при решении о применении конденсаторов на основе кварца на частотах выше 200 МГц. Наличие пьезоэффекта у кварца требует при проектировании электрических цепей с кварцевыми триммерами обязательного учета реактивной мощности, рассеиваемой на конденсаторах, поскольку в условиях, когда реактивная мощность равна активной или превышает ее, происходит быстрое старение кварцевого диэлектрика с последующим его разрушением. Это особенно важно, когда кварцевые переменные или подстроечные конденсаторы используются в силовых или фильтрующих цепях, например, в цепях питания процессоров компьютеров.

\section{Слюдяные конденсаторы}

Слюда относится к материалам, которые традиционно применяются при изготовлении конденсаторов, в том числе переменных и подстроечных. Следует иметь в виду, что в конденсаторах может применяться как природная слюда, так и слюда искусственного происхождения Природная слюда представляет собой один из 28 видов минералов на основе силиката алюминия. Чаще всего в конденсаторах используют так называемый мусковит - силикат алюминия с включением калия. Его химическая формула $\mathrm{K}_{2} \mathrm{Al}_{4} \mathrm{Al}_{2} \mathrm{Si}_{6} \mathrm{O}_{20}(\mathrm{OH})_{4}$. Этот природный минерал легко расщепляется на тонкие прочные пластины, которые и применяются в производстве конденсаторов. Диэлектрическая проницаемость различных видов слюды равна 6-8 (зависит от типа слюды, метода и способа измерения), тангенс угла потерь-0,0004. Электрическая прочность слюды составляет 50-200 кВ/мм, благодаря этому слюдяные конденсаторы могут применяться при рабочих напряжениях до 15 кВ. Тангенс угла потерь равен 0,0004. Для применения в конденсаторах пластины слюды покрываются серебром. Конденсаторы на основе мусковита имеют низкий коэффициент рассеяния на высоких частотах и могут применяться на частотах до 1 ГГц. В зависимости от типа слюды, из которой изготовлен конденсатор, его TKЕ может изменяться от незначительного (менее 90 ppm $/{ }^{\circ} \mathrm{C}$ ) до большого (выше 200 ррm / ${ }^{\circ} \mathrm{C}$ ). Слюдяные конденсаторы характеризуются высоким температурным дрейфом емкости и плохо выдерживают перегрев выше указанной в документации предельной рабочей температуры. При перегреве на поверхности слюды выступают соединения на основе гидроксила (OH), кристаллическая структура слюды становится неустойчивой и в конечном итоге разрушается. Граничная температура, при которой могут применяться конденсаторы на основе мусковита, составляет $500^{\circ} \mathrm{C}$.

Слюды синтетические - это искусственно синтезированные минералы из класса слюды, в которыхгидроксил $(\mathrm{OH})$ заменен ионом фтора. Исходным материалом для получения синтетической слюды служат МgO, $\mathrm{Al}_{2} \mathrm{O}_{3}, \mathrm{SiO}_{2}$ или природное сырье, содержащее указанные окислы. При этом следует иметь в виду, что электрические и механические характеристики искусственной слюды уступают аналогичным характеристикам природной слюды. Поэтому при выборе слюдяных конденсаторов надо тщательным образом выяснять, из какого типа слюды они изготовлены. На настоящий момент основными областями применения переменных и подстроечных конденсаторов на основе слюды являются высоковольтные устройства, мощные источники питания, в том числе импульсные, выходные каскады передающих устройств, демпфирующие устройства.

Несмотря на ряд ограничений по применению слюды в переменных и подстроечных конденсаторах, некоторые компании продолжают их выпускать. В частности, компании Temex Ceramics благодаря ряду технических и технологических решений удалось расширить область применения слюдяных конденсаторов до частот выше 2 ГГц. Конструкция и типовое поведение добротности в зависимости от частоты одной из серий приведены на рис. 14а [17] и рис. 146 [18] соответственно.

\section{Конденсаторы на основе керамических диэлектриков}

Керамические конденсаторы получили свое название потому, что в качестве диэлектрика в них применяется радиочастотная керамика на основе титана, циркония и оксидов других материалов. Чаще всего радиочастотная керамика производится из диоксида титана $\left(\mathrm{TiO}_{2}\right)$, титаната бария $\left(\mathrm{BaTiO}_{3}\right)$ или титаната стронция $\left(\mathrm{SrTiO}_{3}\right)$, хотя точные формулы керамики у разных производителей различаются. Керамические конденсаторы относятся к конденсаторам с нормируемым значением TKE. Ассоциация производителей электронного оборудования (ЕІА) разделяет конденсаторы на основе керамики на четыре класса, 


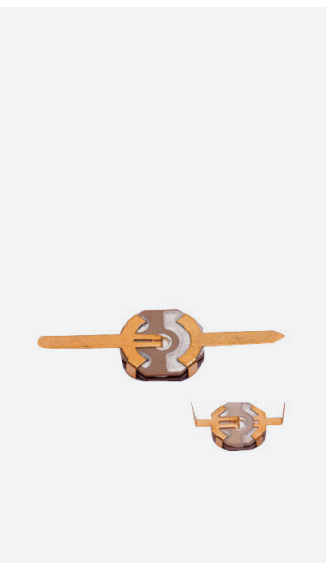

a)

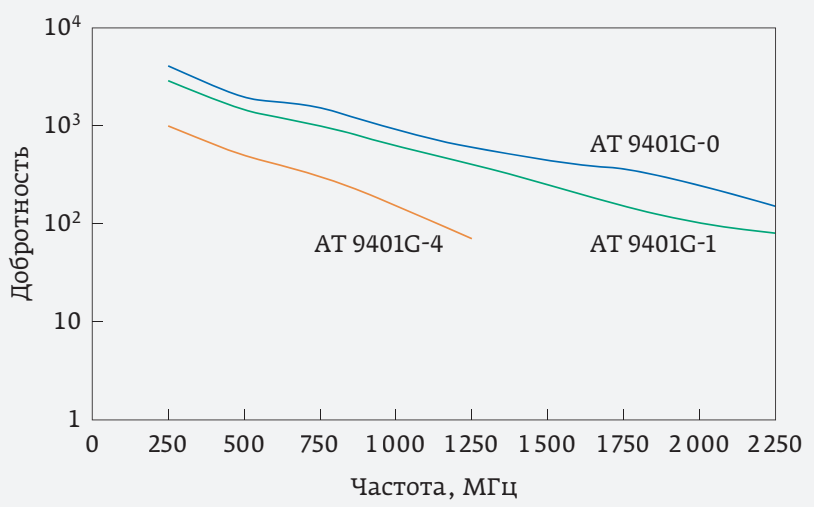

б)

Рис. 14. Триммеры на основе слюды серии AT 9401C компании Temex Ceramics: a - внешний вид; 6 - типичная зависимость добротности от частоты

а также типы внутри каждого класса. Чем меньше номер класса, тем выше общие характеристики конденсатора, но больше размер для данной емкости. Типь в пределах каждого класса определяют рекомендуемый диапазон рабочих температур и ТКЕ, вКлючая температурный дрейф емкости и допуск для него. ЕІА регламентирует основные параметры конденсаторов для каждого класса и методы

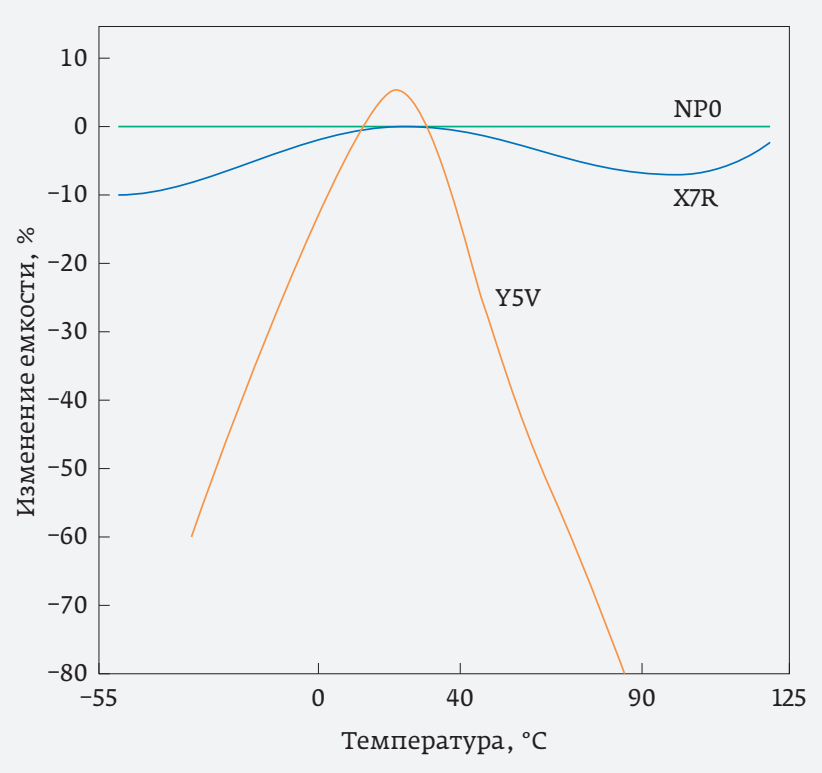

Рис. 15. Температурные зависимости относительного изменения емкости для наиболее распространенных типов керамики, применяемых в производстве керамических триммеров их измерения. Это касается сопротивления изоляции, тангенса угла диэлектрических потерь, диэлектрической абсорбции и других основных параметров конденсаторов. Разделение керамических конденсаторов на классы в достаточной степени условное, поскольку жестких требований для каждого класса не указывается. Например, конденсаторами 1-го класса принято считать "точные конденсаторы с температурной компенсацией, с высокой стабильностьюпо напряжению, температуре и частоте». Конденсаторы 1-го класса характеризуются температурным коэффициентом емкости не хуже $\pm 3 \%$ на градус при $25-85^{\circ} \mathrm{C}$. Для конденсаторов 1-го класса может быть достигнута точность в 1\%, хотя наиболее типичной считается точность 5-10\%. Температурная зависимость емкости для конденсаторов 1-го класса считается линейной. Керамические конденсаторы классифицируют также по типу керамики, которая использована при их изготовлении. Существует несколько вариантов обозначения типа керамики - в соответствии со стандартом EIA-535 и так называемым промышленным стандартом (Industrial). Зависимости относительного изменения емкости от температуры для некоторых типов керамики показаны на рис. 15 [19]. Обозначения типов керамики даны в соответствии со стандартом ЕІА-535.

В зависимости от типа керамики, технологии ее варки и последующей обработки керамические подстроечные и переменные конденсаторы по стоимости могут быть сравнительно дешевыми или дорогими. В дорогих конденсаторах, как правило, используется только керамика класса NPO с электродами, изготовленными из дорогих материалов - золота, платины и их сплавов с другими
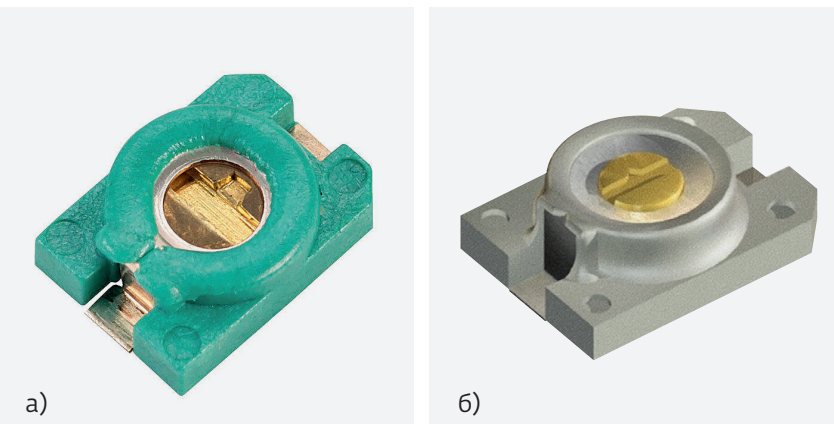

б)

Рис. 16. Дешевый (а) и дорогой (б) триммеры на основе керамических диэлектриков 
металлами. Механическая обработка подвижных частей очень тщательная и исключает возможность люфта и рывков при движении, что крайне важно для плавного изменения емкости. На рис. 16а [20] показаны дешевые триммеры компании Suntan, а на рис. 166 [21] - дорогие триммеры с герметизацией компании Temex Ceramics.

\section{Конденсаторы на основе полимерных пленок}

Данный тип конденсаторов относится к так называемым пленочным конденсаторам (Film), хотя некоторые производители используют название пластиковые (Plastic). В частности, компания Sprague Goodman, специализирующаяся в производстве триммеров, одну из серий своих конденсаторов называет Filmtrim ${ }^{\circledR}$ Plastic Dielectric Capacitors. В качестве диэлектрика в пленочных конденсаторах чаще всего применяются полимерные материалы, например поликарбонат, полиэстер и полипропилен, которые называют "большой тройкой" для пленочных конденсаторов. Эти диэлектрики применяет большинство фирм-производителей таких конденсаторов. Каждый из данных диэлектриков обладает своими особенностями

Поликарбонат. Конденсаторы на основе этого материала имеют низкий температурный дрейф емкости (ниже, чем у других материалов), малые коэффициенты рассеяния и диэлектрической абсорбции. Такие конденсаторы применяются в импульсных цепях и прецизионных аналоговых устройствах, в тех случаях, когда требуется хорошая температурная стабильность и высокий температурный коэффициент емкости. В отличие от других диэлектриков, поликарбонат имеет низкую устойчивость к влажности, что весьма критично в некоторых областях применения.

Полиэстер. Этот материал, вероятно, самый популярный в пленочных конденсаторах, во всяком случае, для монтажа на плату. Полиэстер - это одно из названий класса полимеров на основе полиэтилентерефталата. Зарубежные названия - милар, РЕТ, РЕTE, РЕТР. Конденсаторы на основе полиэстера имеют высокий температурный дрейф емкости, но совместное их подключение с конденсаторами на основе полипропилена позволяет выравнивать кривую зависимости емкости от температуры. Высокое тепловое сопротивление позволяет применять конденсаторы этого типа для поверхностного монтажа.

Полипропилен. Конденсаторы на основе полипропилена (РР) являются самым распространенным типом пленочных конденсаторов. Они выпускаются в очень широком диапазоне размеров и рабочих напряжений и применяются во многих электрических цепях. Конденсаторы на основе РР имеют низкий коэффициент рассеяния во всем диапазоне рабочих температур и в широком диапазоне частот. Это позволяет применять данный тип конденсаторов в высокочастотных цепях и в цепях с высоким током нагрузки, например в импульсных источниках питания. Некоторые типы конденсаторов на основе полипропилена имеют рабочее напряжение выше 400 кВ переменного тока. Малая утечка и низкий коэффициент диэлектрической абсорбции позволяют применять полипропиленовые конденсаторы в интегрирующих цепях и в цепях выборки и хранения. Влияние влажности на эти конденсаторы незначительное. По температурному дрейфу они немногим превосходят конденсаторы на основе полистирола, поэтому их использование ограничено температурой $105^{\circ} \mathrm{C}$ и их невозможно применять для поверхностного монтажа.

В последнее время в качестве диэлектрика также широко применяется полифениленсульфид (PPS).

Металлизацию диэлектрика подстроечных и переменных конденсаторов выполняют либо из фольги (например, тонкой фольги хрома), либо непосредственным напылением на пленку диэлектрика тонкой пленки металла. Компания AVX, в частности, перед напылением металлической пленки проводит предварительную обработку диэлектрика коронным разрядом для лучшего сцепления полимера и металла.

К пленочным триммерам относятся и описанные выше конденсаторы на основе фторопласта-4 (PTFE). Особо

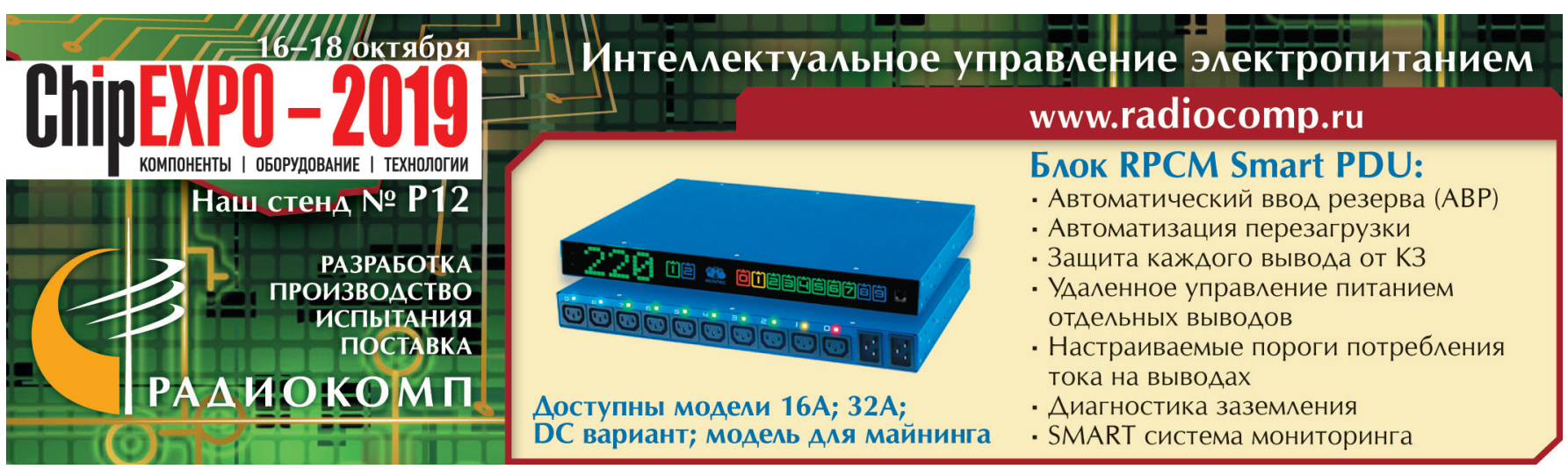




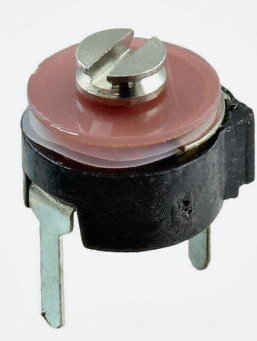

Рис. 17. Пленочный триммер компании Sprague Goodman

следует отметить упомянутую выше серию триммеров Filmtrim ${ }^{\circledR}$ Plastic Dielectric Capacitors компании Sprague Goodman. Технология Filmtrim ${ }^{\circledR}$, разработанная компанией, позволяет получать триммеры, имеющие очень точные и повторяющиеся характеристики, как механические, так и электрические. Эту серию называют так же Six Dielectrics ("Шесть диэлектриков»), поскольку по технологии Filmtrim ${ }^{\circledR}$ изготавливаются триммеры на основе обычного фторопласта-4, высокотемпературного фторопласта-4, полипропилена, полиамида, поликарбоната и полифениленсульфида. На рис. 17 [22] приведена фотография подстроечного конденсатора компании Sprague Goodman, изготовленного на основе высокотемпературного фторопласта-4 (PTFE).

\section{РАЗНОВИДНОСТИ ТРИММЕРОВ ПО КОНСТРУКТИВНОМУ ИСПОЛНЕНИЮ}

В зависимости от назначения, области применения, способа монтажа и материала диэлектрика конструктивное исполнение переменных и подстроечных конденсаторов может быть самым разным. Среди наиболее распространенных конструкций триммеров можно выделить следующие.

Трубчатые триммеры. В самом общем виде трубчатый конденсатор представляет собой цилиндр, на

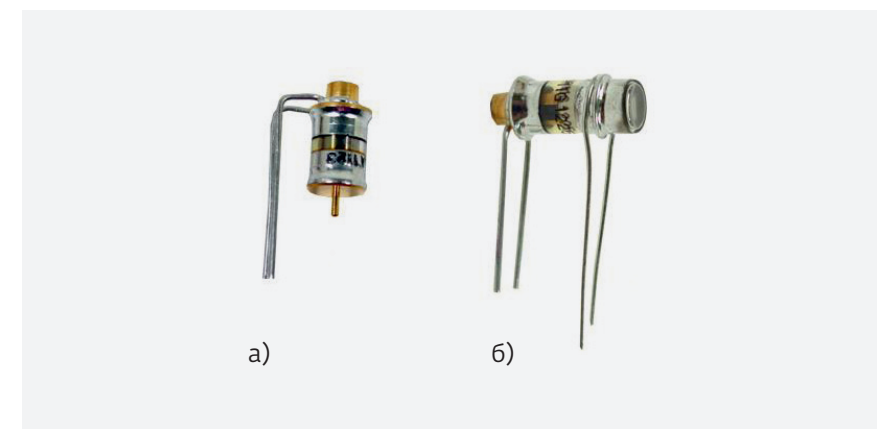

Рис. 18. Стеклянные триммеры компании Voltronics для вертикального (а) и горизонтального (б) монтажа внешнюю и внутреннюю поверхности которого нанесены обкладки. Изменение емкости происходит при перемещении диэлектрического плунжера (сердечника) во внутренней полости цилиндра. Конструктивное исполнение трубчатых триммеров у разных производителей может существенно различаться. В частности, компания Voltronics использует в своих триммерах уникальную конструкцию невращающихся электродов, в которой вращательное движение подстроечной головки (винта) трансформируется в поступательное движение сердечника. При этом сердечник может быть одинарным с внешней металлизацией, либо двойным, представляющим собой две спеченные вместе трубки с серебряной металлизацией между ними. Внутренняя трубка имеет диаметр 0,125 мм для достижения максимальной емкости. Такая конструкция невращающихся электродов обладает рядом преимуществ:

- линейное изменение емкости;

- высокие значения добротности и резонансной частоты конденсатора;

- высокая степень герметизации;

- меньшие габариты при равной емкости;

- возможность применять удлиненные металлические и пластиковые винты для перемещения подвижных частей, чем достигается больший диапазон изменения емкости.

Кроме того, в зависимости от способа монтажа, трубчатые подстроечные и переменные конденсаторы отличаются расположением выводов. На рис. 18 показаны стеклянные триммеры компании Voltronics, предназначенные для вертикальной (рис. 18а [23]) и горизонтальной (рис. 186 [24]) установки на плату.

Триммеры с секционной конструкцией. К данному типу конденсаторов относятся триммеры с плоскими

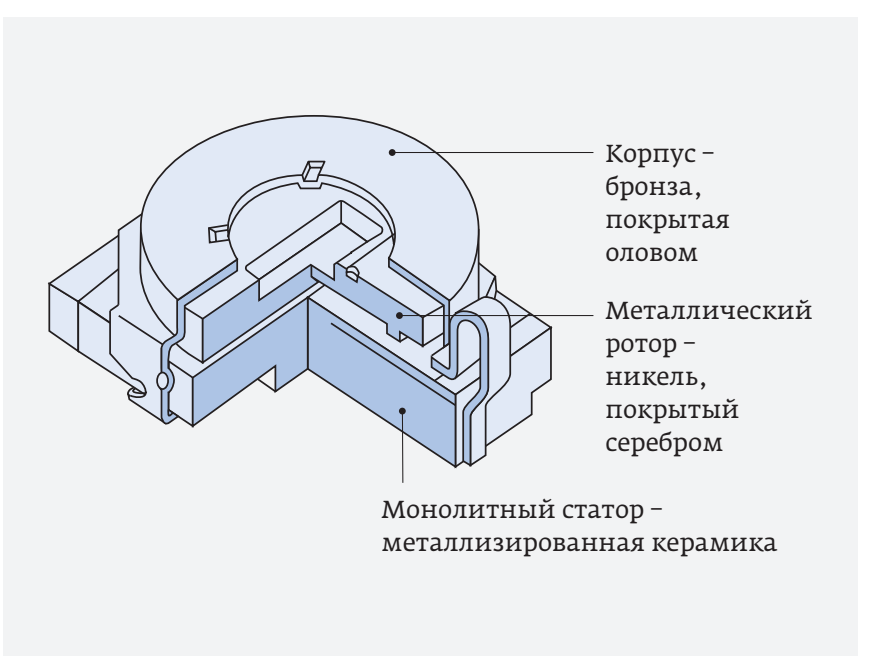

Рис. 19. Конструкция триммера для поверхностного монтажа компании Murata 


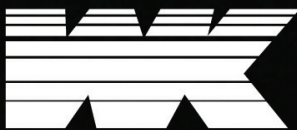

Wayne Kerr

Electronics Ltd

\section{Прецизионные измерители RLC} диапазон частот до 120 МГц

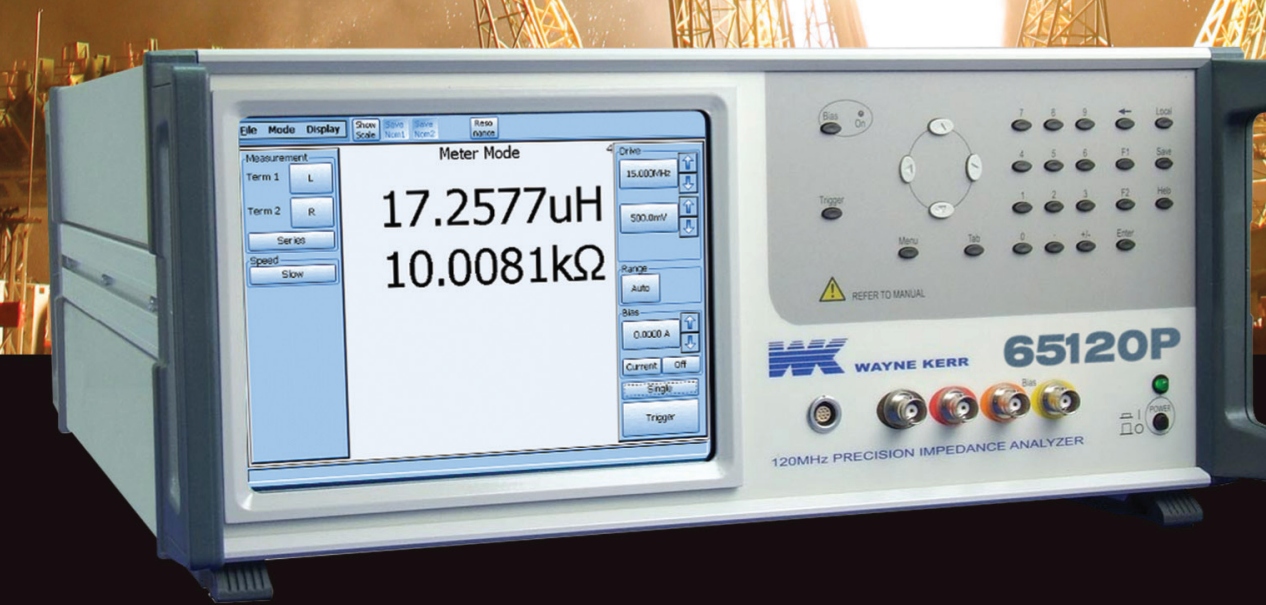

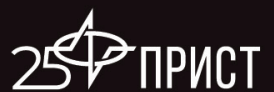

у точности Есть имя!

https://www.prist.ru/

prist@prist.ru

119071, г. Москва, 2-й Донской пр., д. 10, стр. 4; тел.: +7 (495) 777-5591; факс: +7 (495) 640-3023 196006 , г. Санкт-Петербург, ул. Цветочная, д. 18, лит. В, осрис 202; тел./фракс: +7 (812) 677-7508 620089 , г. Екатеринбург, ул. Цвиллинга, д. 58; тел./ракс: +7 (343) 317-3999; ek@prist.ru
Измерители RLC

WK 4310, WK 4320, WK 4350, WK 43100

Прецизионные анализаторы импеданса WK 65120B, WK 6550B, WK 6530B, WK 6520B, WK 6515B, WK 6510B, WK 6505B, WK 65120P WK 6550P, WK 6530P, WK 6520P,

WK 6515P, WK 6510P, WK 6505P

Анализаторы индуктивности 3255B, 3255BL, 3255BQ

Прецизионный анализатор индуктивности WK $3260 \mathrm{~B}$

\section{Прецизионные}

анализаторы компонентов

WK 6430B, WK 6440B

- Быстрое автоматическое тестирование конденсаторов

- Высокая точность определения диэлектрических потерь

- Базовая погрешность 0,02 \%

- Частота тест-сигнала до 3 МГц

- Высокая скорость измерений

- Отображение в виде графика зависимости любого измеряемого параметра от частоты

- Защита от разряда конденсатора

- Интерфейс GPIB 


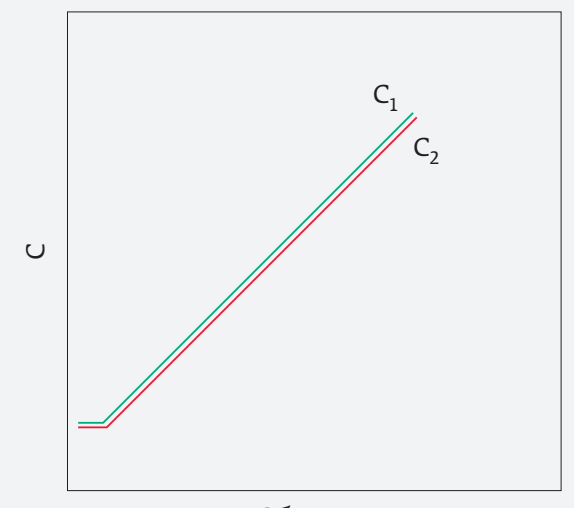

a)

Обороты

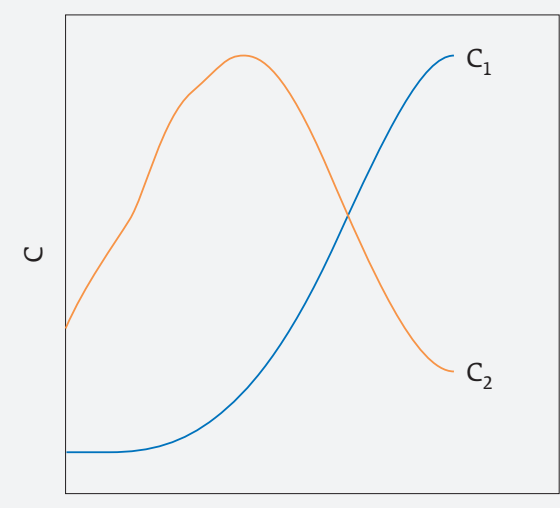

б)
Обороты

Триммеры для навесного монтажа могут содержать до 10 пластин в наборе в зависимости от диапазона емкости.

Кроме того, необходимо отметить переменные и подстроечные $\mathrm{KOH}^{-}$ денсаторы, которые применяются в особых условиях и поэтому должны иметь особое исполнение. К таким конденсаторам нужно отнести немагнитные (non magnetic), высоковольтные (high voltage) и высокочастотные (HiF или Gigahertz) триммеры. Чаще всего исполнение указанных видов триммеров отличается от обычных использованием соответствующих материалов. В частности в немагнитных триммерах обкладки изготавливаются из немагнитных материалов - серебра, сплава сере-

Рис. 20. Изменение емкостей триммера с двумя раздельными статорами (а) и дифференциальной модели (б)

обкладками, которые могут иметь разную форму. Изменение емкости в этой конструкции происходит путем изменения области взаимного перекрытия обкладок конденсатора. Простейший триммер данного типа представляет собой две пластины, перемещающиеся друг относительно друга. Для увеличения емкости, пластины собираются в наборы, перемещающиеся одновременно. Как правило, одна из обкладок неподвижна (статор), а вторая перемещается относительно нее (ротор).

В зависимости от применения, секционные триммеры могут выпускаться в исполнениях для поверхностного или навесного монтажа. Триммеры для поверхностного монтажа, как правило, имеют одну подвижную и одну неподвижную пластины, как это показано на примере триммера компании Murata (рис. 19) [25].

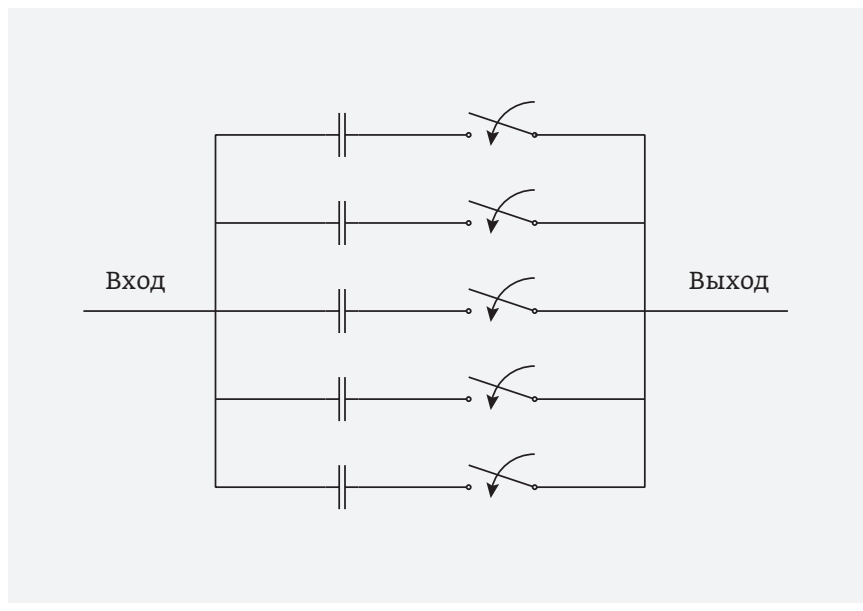

Рис. 21. Функциональная схема триммеров компании pSemi

бра и палладия, сплава серебра и золота. Несущие конструкции, например корпуса, также изготавливаются из немагнитных материалов - стекла или полимерного материала. Внешние выводы и контактные площадки выполняются из меди или латуни, которые покрываются серебром или золотом.

Отдельно следует отметить так называемые многосекционные триммеры. Этот тип конденсаторов имеет несколько роторов или статоров, которые могут быть как зависимы, таки не зависимы один от другого. Особый интерес представляют переменные и подстроечные конденсаторы, которые используются для настройки и подстройки параллельных электрических цепей и контуров. Различают следующие типы многосекционных триммеров:

- с раздельным статором. У этого типа триммеров, как правило, два раздельных статора и общие подвижные обкладки на роторе. По сути, это два или более раздельных конденсаторов, емкость которых меняется примерно с одинаковой скоростью (рис. 20a [26]);

- дифференциальные модели. В триммерах данной конструкции изменение емкости парных конденсаторов происходит противофазно: когда емкость одного конденсатора уменьшается, емкость второго увеличивается. При этом суммарная емкость конденсаторов или общая емкость триммера остается неизменной. Схема этого процесса показана на рис. 206 [27]

\section{ТРИММЕРЫ С ЭЛЕКТРОННЫМ ИЗМЕНЕНИЕМ ЕМКОСТИ}

С развитием цифровыхтехнологий и прогрессом в области миниатюризации электронных компонентов выделился 
еще один тип конденсаторов, отличающихся способом изменения емкости. В большинстве случаев изменение емкости переменных и подстроечных конденсаторов, в том числе и приведенных выше, производится механически поворотом ротора относительно статора. Но в последнее время появился тип конденсаторов, в котором изменение емкости осуществляется цифровым способом. В самом общем виде подобные конденсаторы представляют собой набор параллельно подключенных конденсаторов, соединение которых с общим выводом производится электронными ключами. Типичная блок-схема данного типа конденсаторов приведена на рис. 21 [28].

Компания Peregrine Semiconductor (psemi) специализируется на производстве цифровых управляющих ключей (Tuning Control Switches) и использует их в своих изделиях, в том числе в подстроечных конденсаторах, предназначенных для поверхностного монтажа. на рис. 22 [28] приведен цифровой триммер компании pSemi марки РEG4102.

Необходимо отметить еще один важный момент в последние годы часто обсуждается проблема так называемых немагнитных радиокомпонентов. Подавляющее большинство переменных и подстроечных конденсаторов являются немагнитными. Это связано с тем, что в качестве диэлектрика в них используются материалы, не обладающие магнитными свойствами. Это же касается

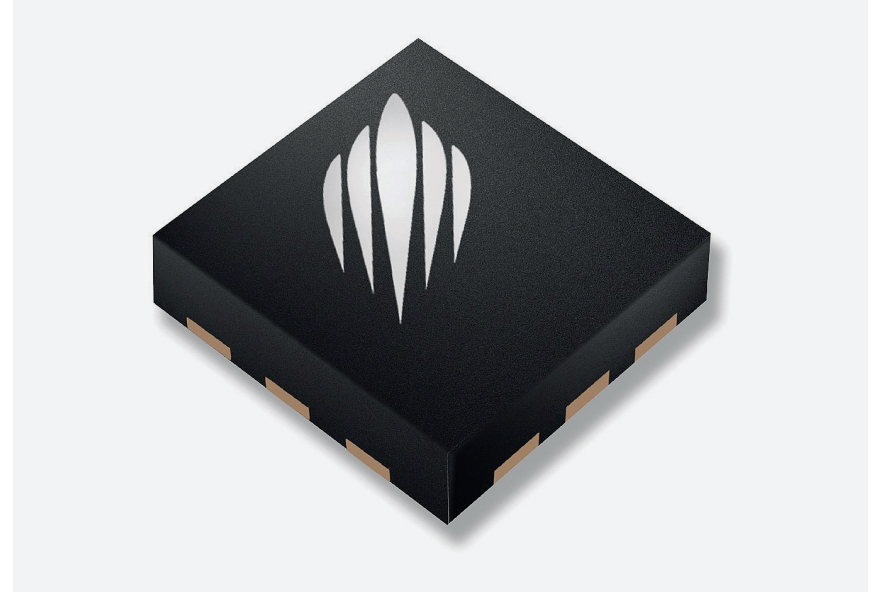

Рис. 22. Внешний вид триммера PE64102 компании pSemi

и металлических частей: чаще всего в триммерах применяются немагнитные металлы - медь, никель, алюминий и их сплавы. Исключением могут являться переменные конденсаторы с воздушным заполнением, обеспечивающие ручную перестройку аппаратуры по частоте в широком диапазоне. Правда, в последние годы данный тип конденсаторов применяется крайне редко и только в специализированной аппаратуре.

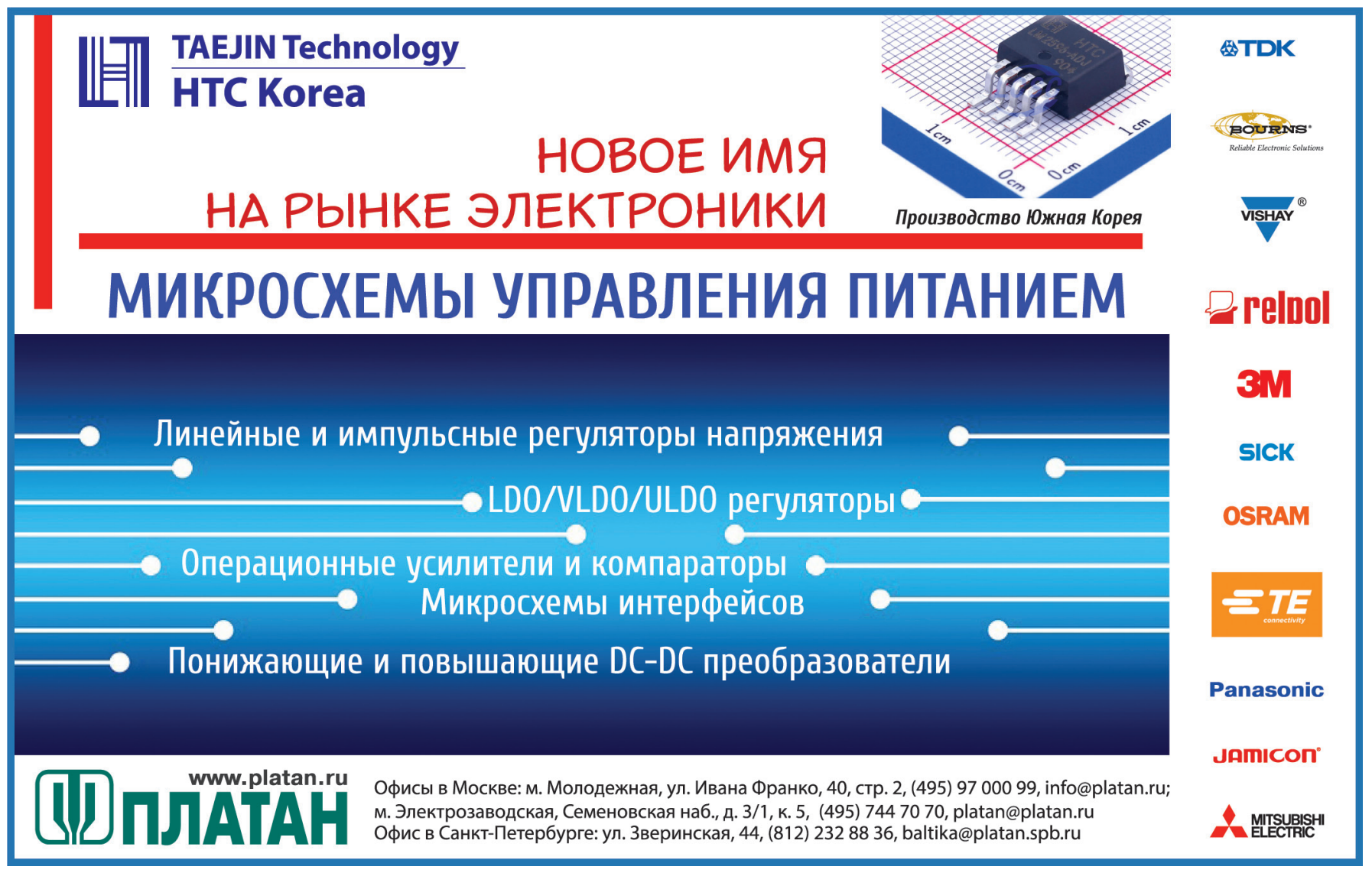




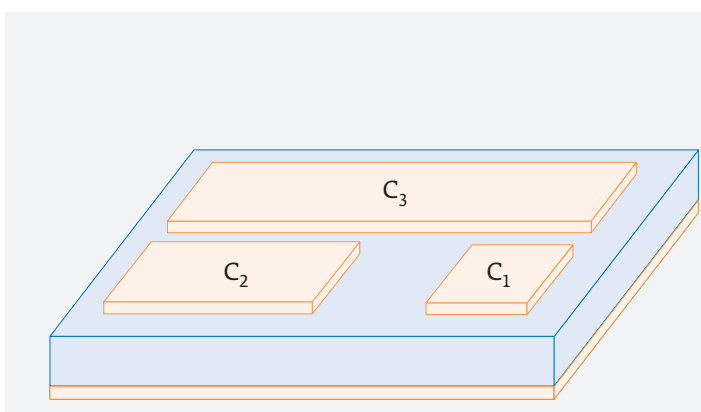

a)

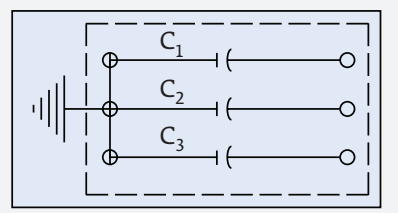

б)

Рис. 23. Общий вид (а) и блок-схема (б) конденсатора серии Ві-Сар ${ }^{\circledast}$ компании Dielectric Laboratories

К категории переменных и подстроечных конденсаторов имеет смысл отнести еще один тип конденсаторов: устройства с двумя или более дискретными значениями емкости. В конденсаторах данного типа одна обкладка выполнена цельной, а вторая представляет собой набор пластин разной конфигурации и размеров. Для получения требуемой емкости либо подсоединяются к пластине, соответствующей той или иной емкости (в соответствии с технической документацией), либо перемыкают соседние пластины. Одни из характерных представителей устройств указанного типа - конденсаторы серий Di-Cap ${ }^{\circledR}$ и Bi-Cap ${ }^{\circledR}$ компании Dielectric Laboratories. На рис. 23 [29] показаны конденсатор серии Ві-Сар ${ }^{\circledR}$ и его блок-схема.

Отдельно следует отметить монтажный и настроечный инструмент, который применяется при перестройке и настройке переменных и подстроечных конденсаторов. Многие производители головки подвижных частей конденсаторов выполняют фигурными, для

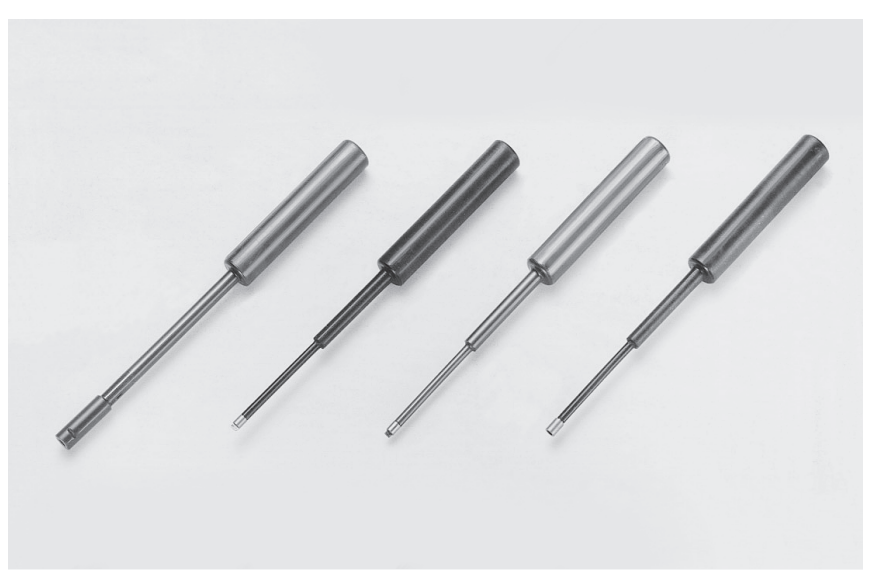

Рис. 24. Настроечные отвертки компании Sprague Goodman

более точной и плавной настройки конденсаторов. Кроме того, будучи установленными в работающие электрические цепи, триммеры требуют применения инструментов, изготовленных из специальных материалов, например немагнитных. На рис. 24 [30] приведена линейка настроечных отверток компании Sprague Goodman.

Таким образом, сегодня существует множество типов переменных и подстроечных конденсаторов. Приведенная в статье информация поможет выбрать устройство, оптимальное для решения той или иной задачи.

\section{ЛИТЕРАТУРА}

15. Материалы компании AVX: Glass Capacitors. P. G.

16. Материалы компании Voltronics: "S" series - Smallest Sealed Glass MIL Trimmer Capacitors.

17. http://www.exxelia.com/en/product/detail/475/thin-trimmers

18. Каталог группы компаний Exxelia: Microwave Components. Ceramic Capacitors, Materials \& Tuning Components. P. 188.

19. Звонарев Е. Пассивные компоненты компании YAGEO // Новости электроники. 2009. № 16. https://www.compel.ru/lib/ne/2009/16/5-passivnyiekomponentyi-kompanii-yageo

20. http://www.suntan.com.hk/Ceramic-Trimmer-Capacitors/ TSC3S.html

21. http://www.exxelia.com/en/product/detail/474/chiptrimmers

22. https://www.digikey.com/products/ en?mpart=GXL4R000\&v=105

23. Каталог Knowles Precision Devices (подразделения компании Knowles Corporation): Trimmers and non-magnetic components. P. 37.

24. Каталог Knowles Precision Devices (подразделения компании Knowles Corporation): Trimmers and non-magnetic components. P. 40

25. Материалы компании Murata: Ceramic Trimmer Capacitors. Cat.No.T13E-14. P. 4.

26. Каталог продукции компании Voltronics. - М.: ООО «Радиокомп", 2009. С. 14.

27. Каталог продукции компании Voltronics. - М.: ООО «Радиокомп", 2009. С. 13.

28. Материалы компании pSemi: UltraCMOS ${ }^{\circledR}$ Digitally Tunable Capacitor. Document No. DOC-89767-1. P. 1.

29. Материалы компании Dielectric Laboratories: Single-Layer and Broadband Blocking Capacitors. P. 22.

30. Материалы компании Sprague-Goodman: Insulated Tuning Tools. Engineering Bulletin SG-206E; P. 2. 